\title{
Structural Equation Modeling in Psychology: The History, Development and Current Challenges
}

\author{
Leila Karimi ${ }^{1,2} \&$ Denny Meyer ${ }^{3}$ \\ ${ }^{1}$ School of Health Sciences, Swinburne University, Melbourne, Victoria, Australia \\ ${ }^{2}$ School of Public Health and Human Biosciences, La Trobe University, Melbourne, Victoria, Australia \\ ${ }^{3}$ The Brain and Psych Sciences Centre, Swinburne University of Technology, Hawthorn, Melbourne, Australia \\ Correspondence: Leila Karimi, Faculty of Life and Social Sciences, Swinburne University, Melbourne, Victoria, \\ 3086, Australia. E-mail: 1.karimi@latrobe.edu.au
}

Received: August 29, 2014

Accepted: September 27, $2014 \quad$ Online Published: November 18, 2014

doi:10.5539/ijps.v6n4p123

URL: http://dx.doi.org/10.5539/ijps.v6n4p123

\begin{abstract}
Structural Equation Modeling (SEM) represents a series of cause-effect relationships between variables combined into composite testable models (Shipley, 2000). It is extensively used by researchers in different disciplines and is a technique often used in psychology.

SEM has attracted attention primarily because it lends itself to effectively studying problems or models that are hard to assess using other procedures. This paper traces the history of SEM in discipline of psychology, and discusses the current developments, the use/misuse of SEM techniques and practical recommendations to direct future research in the discipline.
\end{abstract}

Keywords: structural equation modeling, psychology, latent variable, methodology, SEM history

\section{Introduction}

\subsection{Introduction to Structural Equation Modeling}

Structural equation modeling (SEM) is a major research tool that is rapidly growing in popularity. SEM is defined by some scholars (Pearl, 2000; Wright, 1921) as a statistical technique for testing causal relations, using a combination of statistical data and qualitative causal assumptions. SEM techniques are based on multivariate statistical procedures, which are widely used by researchers in different disciplines. SEM extends on conventional multivariate statistical analysis by accounting for measurement error and by more thoroughly examining goodness-of-fit. The SEM technique has grown out of path and factor analysis.

It is important to understand the history and developments of SEM because this is the lens through which we see the present and the future development of SEM. This lens is restrictive in that it restrains the way we approach research in this area, but it is also beneficial in that it helps us to solve the problems we face today. By understanding the solutions of the past new methods are suggested, and we can learn from the past, making sure that we don't repeat mistakes. As explained by Bollen (1998), in the past people working in this area tended to work independently, often in different disciplines, which meant that progress was not as rapid as it could have been. But even today there are few articles that track the historical progress in areas such as SEM. This paper is therefore designed to contribute to our understanding in this area.

In this study, the history of SEM in psychology will be presented and summarised using a new Time Map presented in Figure 1. This diagram indicates early developments in blue, later developments in yellow, and recent developments in red. Where possible developments in the Big Five Taxonomy will be used to provide examples for each stage of the SEM development. The early roots of SEM will be explored from the work of Pearson (1901) on orthogonal least squares, through to the growth of factor analysis spearheaded by Spearman (1904) and Thurstone (1935). It will be explained how SEM started with path analysis in various disciplines such as psychometrics, sociology, econometrics and biometrics. The interdisciplinary conference of economists, sociologists, psychologists, and statisticians in 1970 greatly influenced the integration of SEM in these disciplines. The work of Bentler (1986) and, more notably, the development of the EQS software in 1970 were significant in the application of SEM in psychology. This study will also explore current developments in SEM 
such as mixed models, meta-analysis and partial least square (PLS). Some of the more controversial debates relating to measurement model misspecification (formative vs. reflective) and the use of PLS-SEM (vs. CB-SEM) will also be discussed. Figure 1 can be utilized as a training tool for both Statistical and Psychology students to better understand the early roots and later developments of SEM. It is hoped that this will help to inspire future developments. It is believed that understanding the fundamentals and philosophy of a topic, creates a longer lasting, less biased in-depth learning experience.

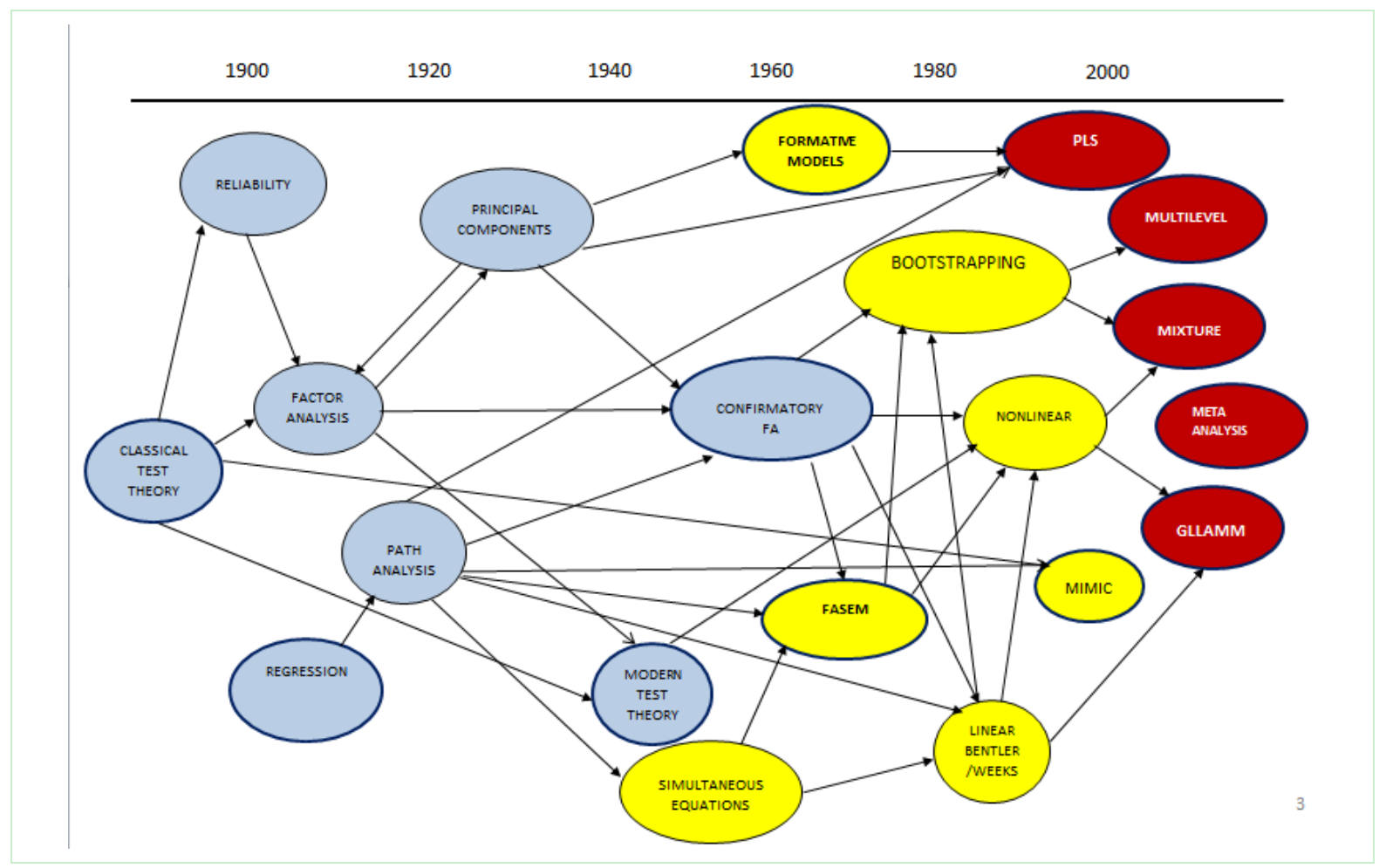

Figure 1. Pseudo path diagram of some developments in SEM model structures

Acknowledgment: Special thanks to Professor Peter Bentler (personal communication, 2012), for his inspiration and input into developing the diagram.

\section{Early Roots of Structural Equation Modeling (shown in blue in Figure 1)}

Exploratory factor analysis (EFA) has made an important contribution in the social sciences by addressing the needs and interests of different disciplines. The primary roots of SEM in psychology belong to Pearson's (1901) theory on orthogonal least squares. Pearson's theory was not fully appreciated at the time, but later it became a foundation for principal component analysis and correlation matrix analysis (Hotelling, 1933). Spearman (1904), an English psychologist, also contributed substantially. He is commonly regarded as the pioneer of factor analysis given his work involving the finding of relationships between multiple correlated measures of cognitive performance.

Using factor analytic data, Spearman postulated his original two-factor models of ability and intelligence testing, highlighting the theory testing nature of the method. Other scholars gradually adopted this theory testing trend using factor analysis (e.g. Anderson \& Rubin, 1956; Guttman, 1952; Lawley, 1940; Mosier, 1939).

Spearman's two-factor theory was criticised widely (e.g. Thomson, 1916 \& 1935; Wilson, 1928, 1929). Between 1940 and 1951, factor analytic literature became increasingly atheoretical and the focus of criticism shifted to technical refinement. For these scholars, the Spearman two-factor methods were not appropriate for practical situations that involved the frequently encountered group factors. In 1931, Thurstone considered this to be one of the serious limitations of Spearman's method, mainly because psychological problems usually involve group factors (Thurstone, 1935). This limitation led to an interest in multiple factor analysis to supplement Spearman's model, whereby group factors were identified after extracting a general factor (e.g., Holzinger 1941). 
Consequently, during this period some significant progress in statistical analysis occurred. One of the important advances in this period was perhaps the popularisation of multiple factor analysis.

It was during this period that Cattell (1945) derived the first personality model consisting of 12 factors using oblique factor analyses. The 35 items comprising these factors eventually became part of his 16PF Questionnaire (Cattell, Eber, \& Tatsuoka, 1970). However later work suggested a clerical error with this analysis (Tupes \& Christal, 1961) and some disagreement with the number and nature of the factors, although the second-order factors of the 16PF show some correspondence with the subsequent Big Five dimensions (Digman \& Tatsuoka, 1970).

In practice the centroid method of factor analysis of Thurstone (1947) operated successfully and part of its theoretical background was recognised in the 1960s (Bentler, 1968; McDonald, 1970). However, from early 1980 the explicit optimisation functions used in factor analysis (such as least square, maximum likelihood (ML), minimum chi-square, etc.) became more popular.

The problem of rotating factor was avoided when confirmatory factor analysis (CFA) was introduced. In CFA, the number and patterns of factors and their loadings are specified at the start, transforming the problem into one of identification of a model's parameters from observed moments (Matsueda, 2012).

CFA was introduced originally by Tucker (1955) with Bechtold undertaking one of the early studies in 1961. By introducing an ML approach to factor analysis (Anderson \& Rubin, 1956; Lawley, 1940), further development of CFA occurred. It was Jöreskog (1969) who made the method practical and developed computer software programs for CFA estimates using ML.This method was used by many authors to further refine and develop a model of personality.

But in addition to the early SEM work on measurement there was also some very early work on path analysis. Sewall Wright was the first to use path analysis in medical science when he started using it in his studies in the 1920s. Path analysis was one of the primary methods used to determine a causal structure. Wright used observed variables to develop a correlation matrix, and drew path diagrams indicating direct and indirect effects such as that found in Figure 2.

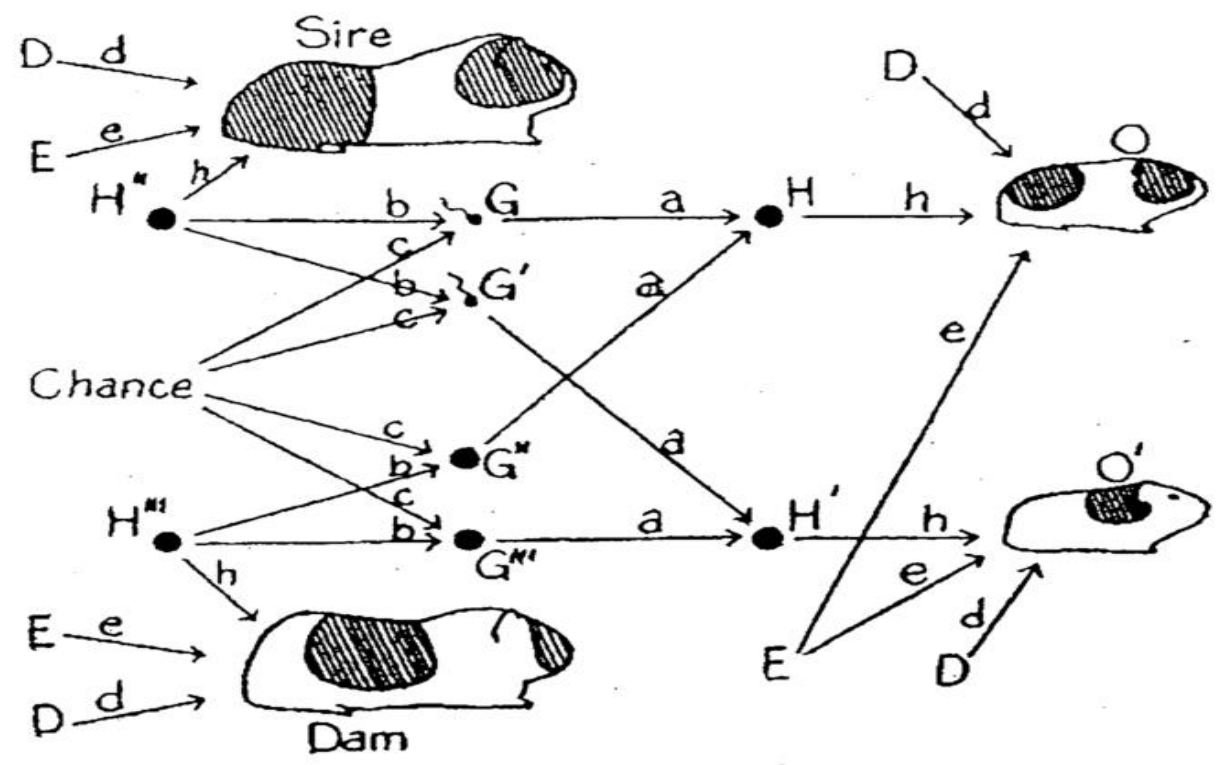

Figure 2. One of Wright's first path diagrams for genetic modelling

Source: Wright, Sewall (1920). The relative importance of heredity and environment in determining the piebald pattern of guinea-pigs. Proceedings of the National Academy of Sciences, 6, 320-332. 


\section{Developments of SEM}

\subsection{Simultaneous Equation Models in Economics}

The development of SEM in econometrics can be attributed perhaps to Frisch and Waugh (1933), Haavelmo (1943) and Koopmans (1945). Frisch (1934), the founder of the Econometric Society and the Econometrica journal, invented the term "econometrics" and developed many of the principles of identification for SEM. Haavelmo (1943) was another economist who made some significant contributions. The advances made by Haavelmo, and Mann and others, led to work on SEM at the Cowles Commission (1952). This resulted in Haavelmo solving the major problems of identification, estimation, and testing for SEM.

According to Bentler (1986), one of the pioneer researchers was Goldberger, who introduced the integration of ideas related to SEM in different disciplines (e.g., Goldberger, 1971). This integration of ideas was one of the turning points in the evolution of SEM in the 1970s.

\subsection{FASEM (Factor Analysis SEM)}

FASEM is a generic acronym for factor analysis (FA) and structural equation modeling (SEM) which saw major development in the 1970s and 1980s. It was first used by Bentler (1986), to refer to conceptual approaches for modeling with continuous variables in SEM.

The Conference on Structural Equation Models in 1970 contributed greatly to the integration of SEM disciplines. The conference was an interdisciplinary forum of economists, sociologists, psychologists, statisticians, biometricians and political scientists and the academic papers were published by Goldberger and Duncan in a volume of Structural Equation Models in the Social Sciences in 1973. The factor analysis of structural equation modeling (FASEM) and linear structural relations (LISREL) were the main outcomes of this integration. At the time, simultaneous equation and path analysis methods were the main contributors to FASEM and LISREL.

According to Bentler (1986), the major achievements in the 1970s can be categorised into three sections: structural concepts, statistical theory and practical development. The two key papers published in this period were written by Hauser and Goldberger (1971) and Jöreskog (1973). Hauser and Goldberger's (1971) examination of unobservable variables is an exemplar of cross-disciplinary integration, drawing on path analysis and moment estimators developed by Wright in the 1920s and various sociologists. It also incorporates factor-analytic models from psychometrics, efficient estimation, and Neyman-Pearson hypothesis testing from statistics and econometrics. Hauser and Goldberger used limited information estimation to gain a better understanding of structural equations estimated by ML. Jöreskog (1973). They presented an ML framework for estimating SEMs, developed a computer program for empirical applications, and showed how the general model could be applied to a myriad of important substantive models.

Goldberg (1981) has been credited with the naming of the "Big Five" after numerous researchers (e.g. Norman (1963), Borgatta (1964), Digman and Takemoto-Chock (1981)) were able to replicate the five factor structure foreshadowed in Cattell's work using lists of items derived from Cattell's original 35 items. However, it was acknowledged that these five dimensions represented personality only at the broadest level of abstraction. Cross-language research by Hofstee et al. (1997) suggests that although the Big Five can be replicated in Germanic languages, evidence in non-Germanic languages is less convincing (John et al., 1999).

\subsection{Linear Bentler-Weeks and Nonlinear SEMs}

There is evidence that the turning point in the application of SEM in psychology dates back to the 1970s and 1980 s, primarily through the work of Bentler and, more particularly, the development of the EQS structural equation modeling software (Matsueda, 2012). Using such analytical software for evaluating their models allows researchers to make better use of their data and to study the empirical applications of several new methods proposed in the literature (Bentler, 1986). During the 1980s some researchers paid attention to nonlinear SEMs, which helped to extend the overall scope of SEM. Some important developments in nonlinear latent variable SEM, particularly those for categorical data, appeared in the 1980s, mainly in the works of Bock and Aitkin (1981), Mislevy (1984) and Muthén (1984).

\subsection{Formative Models}

The first appearance of formative measures possibly goes back to the Berkson error model for radiation epidemiology studies in the 1950s. In Classical Test Theory (CTT), the observed score is considered equal to the true score plus measurement error, while in the Berkson error model the true score is equal to the observed score plus measurement error (Carroll, Ruppert, Stefanski, \& Crainiceanu, 2006). This concept has become known as the Berkson measurement error and is the cornerstone of what is today known as formative models. Although the 
concept of formative measures was introduced by Berkson in 1950, it did not attract enough attention until the late 1960s. While many scholars (e.g. Blalock, 1971; Bollen, 1989; Diamantopoulos \& Winklhofer, 2001; Jarvis et al., 2003; Petter, Straub, \& Rai, 2007) have alerted researchers to the relevance of formative models in specific situations, these models have been underemphasized in the literature.

Although the dimensions of personality cannot be viewed as formative because they reflect the personality rather than cause personality there are many other formative indicators in psychology. An example quoted by Hoyle (2011) concerns measures of life stress. The occurrence of each stressful event increases life stress and failure to include all such events will result in an incomplete measure of life stress.

\subsection{Multiple-Indicators Multiple-Causes Model (MIMIC)}

One of the models that was estimated by Wright in the 1920s using path analysis, is similar to what is now known as a MIMIC model (Matsueda, 2012). The main advancement in MIMIC was achieved through the works of Jöreskog and Goldberger and Hauser, and Goldberger in the 1970s. They introduced maximum likelihood as the estimation method for over-identified MIMIC models.

These MIMIC models were used by John et al. (1999) to test the convergence and discriminant validity for three personality instruments; Goldberg's(1992) TDA, Costa and McCrae's (1992) NEO questionnaire and the John et al. (1881) BFI. They found that the Big Five are "fairly independent dimensions that can be measured with convergent and discriminant validity". However, their CFA analysis of this model confirmed that "five latent, modestly correlated personality factors capture the major sources of variance" and that three smaller method factors represented the "trait-specific variance" for the three instruments.

The release of the LISREL statistical software by Jöreskog in the 1970s has produced the biggest advancement in estimating MIMIC models. LISREL is still popular among scholars because of its ability to incorporate factor analysis, path analysis, SEMs into a general covariance structure model (Jöreskog and Sörbom 2001; Matsueda, 2012). Using the MIMIC model, identification and estimation of formative models has become feasible.

\section{The current Developments in SEM}

Some of the most current developments in SEM include multilevel-mixture models, generalized linear latent and mixed modelling (GLLAMM), partial least square (PLS) and SEM-based meta-analysis.

\subsection{Multilevel and Mixture Models}

Using multilevel SEM, separate models for within and between group covariances are modeled. Further, by using a multiple group analysis, the parameters can be calculated simultaneously for both levels (Muthén, 1994). Although this estimation method can be applied using almost any SEM software, this is generally only for a few specific models.

Many personality meta analyses and multi-level analyses have been conducted. For instance Linden et al (2010) have provided a meta-analysis for a general factor of personality (GFP), providing robust support for a GFP in a SEM analysis involving 212 studies, while Roesch et al. (2010) provide a multi-level SEM (MSEM) to show the effect of coping strategies on positive and negative affect using daily diary data.

\subsection{GLLAMM}

As mentioned above, the use of multilevel models is limited to specific models and cannot be applied to all models. In response to this limitation, a more advanced and general estimation method, GLLAMM, was introduced by Rabe-Hesketh, Skrondal \& Pickles (2004), and further developed by Skrondal and Rabe-Hesketh's (2004). GLLAMM has three main components: a generalized linear model, a structural equation model for latent variables, and distributional assumptions for latent variables (Matsueda, 2012). The generalized linear model is capable of analysing all types of data; continuous, ordinal, dichotomous and discrete. The GLLAMM program is now part of the Stata program. Many of the GLLAMM models can also be analysed by MPlus which is another powerful software package, developed by Muthén and Muthén (2004).

\subsection{Partial Least Squares (PLS)}

The roots of PLS, as well as graphical models, can be traced to Herman Wold in 1977 (Geladi, 1988). PLS modeling was then extended into the SEM area while entertaining principal component analysis.

Originally, PLS was developed to solve the problem of multicollinearity in multiple regression analysis. According to Wold (1979), PLS regression was an appropriate estimation method in complex models with undeveloped theoretical backgrounds. The original application of PLS was more for predictive models (Barclay, Higgins, and Thompson, 1995). Later, as an alternative to Jöreskog's covariate-based SEM (CB-SEM) approach, 
Wold introduced SEM based on PLS. Because PLS-based SEM has fewer underlying restrictions, such as normally distributed data and large sample size, it came to be known as "soft modelling". Despite the less restrictive nature of PLS-based SEM, it is still not as popular as covariate-based SEM. The main reason for this previously was a lack of software for model estimation, but this problem is now being addressed.

Since 1984, and especially from the early 2000s, more user-friendly software has been introduced for the estimation of PLS-based SEM, adding to the popularity of the method. Software such as LISREL (Jöreskog, 1977), MPlus (Muthén \& Muthén, 2004), PLS-GUI (Li, 2005), Visual PLS (Fu, 2006a), PLS-Graph (Chin, 2004), SmartPLS (Ringle et al. 2005), SPAD-PLS (Test\&Go, 2006) and XLSTAT (Addinsoft, 2008) are some of the recent developments in this area (Morales, 2011). There have been many debates among the scholars on the application of PLS and the lack of an overall goodness-of-fit test, and the implications of this are discussed in the next section briefly.

\subsection{SEM-Based Meta-Analysis}

The concept of SEM-based meta-analysis was introduced by Cheung (2008). Cheung developed a SEM framework for integrating SEM results from different studies. Based on this approach, studies in meta-analysis can be considered as subjects in SEM. Although the proposed approach added a new and important methodological development in SEM, it is not yet fully incorporated into the current popular SEM software, limiting its further application in practice.

\section{Discussion}

SEM is rapidly growing in popularity as a major research tool in psychology. The early foundation of SEM can be traced back to factor analysis, principal component analysis, regression and path analysis. It started in various disciplines such as psychometrics, sociology, econometrics and biometric path analysis. The interdisciplinary conference in 1970 greatly influenced the integration of SEM disciplines. The work of Bentler and, especially, the development of the structural equation modeling software (EQS) in 1970 was another turning point for the application of SEM in psychology. Since then, SEM has rapidly developed through different approaches such as linear Bentler-Weeks, MIMIC, FASEM, and formative models. Other recent development such as PLS, GLLAMM, multilevel and mixture models have extended the application of SEM techniques to a higher level.

Although this area is progressing rapidly, there is a danger that the technique will be misused due to its complexity or insufficient knowledge of psychological researchers. Some of the most controversial debates relate to model misspecification (formative vs. reflective) and the use of PLS-SEM (vs. CB-SEM). These two issues are described in more detail in the next section to highlight their importance.

\subsection{The Use or Misuse of SEM}

\subsubsection{Formative vs. Reflective Models}

One of the recent debates in SEM concerns measurement model misspecification. The existing evidence of SEM model misspecification reveals that the distinction between formative and reflective indicators needs to be clarified. When indicators are affected by a latent variable, reflective models are appropriate. However, in many settings, where indicators are the cause of a latent variable, formative models are deemed to be more accurate and appropriate.

By default, most researchers assume that models are reflective. Many scholars (e.g. Blalock, 1971; Bollen, 1989; Diamantopoulos and Winklhofer, 2001; Jarvis et al., 2003; Petter et al., 2007) have alerted researchers to the relevance of formative models in some specific situations. However, this message is often lost in the literature.

According to Fornell and Bookstein (1982), in reflective models the items are indicators of a latent factor. These models provide the trigger for reliability evaluation and common/confirmatory factor analysis (Bollen 1989; Long, 1983; Nunnally, 1978).

Conversely, depending on the nature of the measure, the indicators might cause the construct (Bollen \& Lennox, 1991). When the construct is moulded by its measures, a formative model is suggested (Fornell \& Bookstein, 1982). Based on what has been discussed in the preceding section, it is crucial to provide a clear, well-defined decision-making framework for assessing reflective and formative models.

Because of misspecification, some of the findings in the literature might be misleading (Jarvis et al. 2003; MacKenzie et al. 2005; Petter, Straub, \& Rai, 2007). Although there are strong guidelines for fitting reflective models, less is known about procedures for fitting formative models. In recent years, a few scholars have paid attention to formative indicators and have suggested specific guidelines for the appropriate use of these models 
(Diamantopoulos \& Winklhofer, 2001; Jarvis et al., 2003; Petter et al., 2007). More attention to measurement model specification is needed for future studies using SEM.

\subsubsection{PLS-SEM vs. CB-SEM}

Debate over the use of covariate-based SEM (CB-SEM) over partial least square-SEM (PLS-SEM) has existed from the early years of development of these procedures. In particular some scholars have been questioning the practicality and generalisability of the PLS method for factor estimation.

In spite of the wide criticism of PLS in the literature, PLS has specific strengths in certain situations which have been misunderstood or ignored by CB-SEM proponents. A comparison of some of the main features of both approaches, along with some of the existing criticisms, will be presented below.

Prediction validity. The literature shows that PLS has great capability as a prediction tool, a fact that has not been fully appreciated. PLS is considered to be a good inferential tool, a correct method for formative constructs and for developing measurements with new theoretical or empirical backgrounds (Ridgon, 2012). Pro-PLS scholars believe that by using research data, one can help in building empirical background and unobservable conceptual variables (Ridgon, 2012). On the other hand, CB-SEM followers believe that one should specify a conceptual structure and seek evidence regarding whether these structures are consistent with empirical evidence, so that results can challenge, support, or modify those conceptualizations.

Fit assessment test. CB-SEM assesses the overall fit of the model using the covariance among the items, assuming that all measures are reflective, with less interest in the individual effects of construct or path coefficients. In contrast, PLS does not rely on item covariance and overall goodness-of-fit; instead, the focus is on the variances of predicted variables or construct variances (Chin, 2010). Thus, in practice, in the presence of formative constructs, PLS might be a better choice than CB-SEM.

Theoretical background. Due to the holistic and confirmatory approach of CB-SEM, it is more useful when there is solid theoretical and background knowledge for the model. In contrast, a PLS approach, with its exploratory nature and focus on the significance and strengths of individual paths and constructs, seems to be an appropriate procedure for new models, and particularly useful in behavioural and social sciences when there is limited background knowledge of the expected model (Chin \& Newsted, 1999; Chin, 2010; Roldán \& Sánchez-Franco, 2012).

Normality assumption. CB-SEM commonly uses ML estimation assuming a normal distribution for the data, while, for PLS, there is no underlying assumption for the data distribution. This means that, for non-normal data, the use of variance-based PLS is justified when sample sizes are too small to allow asymptotically distribution-free CB-SEM or bootstrap analyses.

Sample size. One of the requirements of using CB-SEM is having a relatively large sample size, while PLS can be conducted with small sample sizes. In PLS, the estimators are inconsistent and biased, in that standard errors do not decline with increasing sample size and expected parameter estimates do not converge to their true values. In CB-SEM models, if the underlying assumptions are met, consistency is ensured.

PLS-SEM and CB-SEM are two different approaches for estimating SEM models. Each approach is suitable for a specific context. Researchers need to appreciate the differences between the methods in order to use the more appropriate approach (Hair, Black, Babin, \& Anderson, 2010; Hair, Ringle, \& Sarstedt, 2011; Hair, Hult, Ringle, Sarstedt, 2014). As acknowledged by Hair et al.(2011), neither model is superior to the other and "depending on the specific empirical context and objectives of a SEM study, PLS-SEM's distinctive methodological features make it a valuable and potentially better-suited alternative to the more popular CB-SEM approach" (p. 149).

\section{Acknowledgments}

The idea of using a diagram to show the history of SEM came from a personal conversation with Professor Peter Bentler in 2012. The researchers were inspired by the idea and extensively developed the diagram to include all the premier and influential developments in SEM over time.

\section{References}

Anderson, T. W., \& Rubin, H. (1956). Statistical inference in factor analysis. Proceedings of the Third Berkeley Symposium on Mathematical Statistics and Probability. Berkeley: University of California Press.

Barclay, D., Higgins, C., \& Thompson, R. (1995). The Partial Least Squares (PLS) Approach to Causal Modeling: Personal Computer Adoption and Use an Illustration, Technology Studies, 2, 285-309.

Bentler, P. M. (1968). Alpha-maximized factor analysis (Alphamax): Its relation to alpha and canonical factor 
analysis. Psychometrika, 33, 335-345. http://dx.doi.org/10.1007/BF02289328

Bentler, P. M. (1986). Structural modeling and psychometrika: An historical perspective on growth and achievements. Psychometrika, 51(1), 35-51. http://dx.doi.org/10.1007/BF02293997

Blalock, H. M. (1971). Causal models in the social sciences. Chicago: Aldine-Atherton.

Bock, R. D., \& Aitkin, M. (1981). Marginal maximum likelihood estimation of item parameters: Application of an EM algorithm. Psychometrika, 46, 443-459. http://dx.doi.org/10.1007/BF02293801

Bogatta, E. F. (1964). The structure of personality characteristics, Behavioral Science, 9, 8-17. http://dx.doi.org/10.1002/bs.3830090103

Bollen, K. A. (1989). Structural equations with latent variables. New York: Wiley. http://dx.doi.org/10.1002/9781118619179

Bollen, K. A., \& Lennox, R. (1991). Conventional Wisdom on Measurement: A Structural Equation Perspective. Psychological Bulletin, 110, 305-314. http://dx.doi.org/10.1037/0033-2909.110.2.305

Bollen, K. A. (1998). Path Analysis. Encyclopedia of Biostatistics. Online: John Wiley \& Sons.

Carroll, R. J., Ruppert, D., Stefanski, L. A., \& Crainiceanu, C. M. (2006). Measurement Error in Nonlinear Models: A Modern Perspective (2nd ed.). Chapman and Hall/CRC Press: Boca Raton. http://dx.doi.org/10.1201/9781420010138

Cattell, R. B. (1945). The description of personality: Principles and findings in a factor analysis. American Journal of Psychology, 58, 69-90. http://dx.doi.org/10.2307/1417576

Chin W., \& Newsted, P. (1999). Structural Equation Modeling Analysis with Small Samples Using Partial Least Squares. In R. Hoyle (Ed.), Statistical Strategies for Small Sample Research (pp. 307-341). Sage Publications.

Chin, W. W. (2010). Bootstrap cross-validation indices for PLS path model assessment. In V. E. Vinzi, W. W. Chin, J. Henseler, \& H. Wang, (Eds.), Handbook of Partial Least Squares: Concepts, Methods and Applications (pp. 83-97). Springer-Verlag, Berlin. http://dx.doi.org/10.1007/978-3-540-32827-8_4

Cheung, M. W. (2008). A Model for Integrating Fixed-, Random-, and Mixed-Effects Meta-Analyses Into Structural Equation Modeling. Psychological Methods, 13(3), 182-202. http://dx.doi.org/10.1037/a0013163

Costa, P. T., \& McCrae, R. R. (1992). NEO PI-R Professional manual. Odessa, FL: Psychological Assessment Resources.

Diamantopoulos, A., \& Winklhofer, H. (2001). Index Construction with Formative Indicators: An Alternative to Scale Development. Journal of Marketing Research, 38(2), 269-277. http://dx.doi.org/10.1509/jmkr.38.2.269.18845

Digman, J. M., \& Takemoto-Chock, N. K. (1981). Factors in the natural language of personality: Reanalysis and comparison of six majot studies. Multivariate Behavioral Research, 16, 149-170. http://dx.doi.org/10.1207/s15327906mbr1602_2

Frisch, R. (1934). Statistical confluence analysis by means of complete regression systems. Oslo: Osto University.

Frisch, R., \& Waugh, F. (1933). Partial Time Regressions as Compared with Individual Trends. Econometrica, 1(4), 387-401. http://dx.doi.org/10.2307/1907330

Fornell, C., \& Bookstein, F. L. (1982). Two Structural Equation Models: LISREL and PLS Applied to Consumer Exit-Voice Theory. Journal of Marketing Research, 19(4), 440-452. http://dx.doi.org/10.2307/3151718

Geladi, P. (1988). Notes on the History and Nature of Partial Least Squares (PLS) Modeling. Journal of Chemometrics, 2, 231-246. http://dx.doi.org/10.1002/cem.1180020403

Goldberg, L. R. (1981). Language and individual differences: The search for universals in personality lexicons. Review of personality and social psychology, 2, 141-165.

Goldberg, L. R. (1992). The development of markers for the Big-Five factor structure. Psychological Assessment, 4, 26-42. http://dx.doi.org/10.1037/1040-3590.4.1.26

Goldberger, A. S. (1971). Econometrics and psychometrics: A survey of communalities. Psychometrika, 36, 83-107. http://dx.doi.org/10.1007/BF02291392

Goldberger, A. S., \& Duncan, O. D. (Eds.). (1973). Structural equation models in the social sciences. New York. 
Guttman, L. (1952). Multiple group methods for common factor analysis: Their basis, computation, and interpretation. Psychometrika, 17, 209-222. http://dx.doi.org/10.1007/BF02288783

Haavelmo, T. (1943). The Statistical Implications of a System of Simultaneous Equations. Econometrica, 11, 1-12. http://dx.doi.org/10.2307/1905714

Hair, J. F., Black, W. C., Babin, B. J., \& Anderson, R. E. (2010). Multivariate Data Analysis (7th ed.). Prentice Hall, Englewood Cliffs.

Hair, J. F., Ringle, C. M., \& Sarstedt, M. (2011). PLS-SEM: Indeed a silver bullet. Journal of Marketing Theory and Practice, 19(2), 139-151. http://dx.doi.org/10.2753/MTP1069-6679190202

Hair, J. F., Hult, G. T. M., Ringle, C. M., \& Sarstedt, M. (2014). A Primer on Partial Least Squares (PLS) Structural Equation Modeling. Los Angeles: Sage.

Hauser, R. M., \& Goldberger, A. S. (1971). The Treatment of Unobservable Variables in Path Analysis. Sociological Methodology. http://dx.doi.org/10.2307/270819

Hofstee, W. K., Kiers, H. A., De Raad, B., Goldberg, L. R., \& Ostendorf, F. (1997). A comparison of Big-Five structures of personality traits in Dutch, English and German. European Journal of Personality, 11, 15-31. http://dx.doi.org/10.1002/(SICI)1099-0984(199703)11:1<15::AID-PER273>3.0.CO;2-8

Holzinger, K. J. (1941). Factor Analysis. Chicago: University of Chicago Press.

Hotelling, H. (1933). Analysis of a Complex of Statistical Variables into Principal Components. Journal of Educational Psychology, 24, 498-520. http://dx.doi.org/10.1037/h0070888

Hoyle, R. H. (2011). Structural equation modelling for social and personality psychology. Beverley Hills, CA: Sage.

Irwin, J. O. (1935). On the indeterminacy in the estimate of g. British Journal of Psychology, 25, 393-394.

Jarvis, C., MacKenzie, S., \& Podsakoff, P. A. (2003). Critical Review of Construct Indicators and Measurement Model Misspecification in Marketing and Consumer Research. Journal of Consumer Research, 30(2), 199-218. http://dx.doi.org/10.1086/376806

Jennrich, R. I., \& Clarkson, D. B. (1980). A Feasible Method for Standard Errors of Estimate in Maximum Likelihood Factor Analysis. Psychometrika, 45, 237-247. http://dx.doi.org/10.1007/BF02294078

John, O. P., Donahue, E. M., \& Kentle, R. L. (1991). The Big Five Inventory-Versions 4a and 54. Berkley, CA: University of California, Berkley, Institute of Personality and Social Research.

John, O. P., \& Srivastava, S. (1999). The Big-Five trait taxonomy: History, measurement, and theoretical perspectives. In L. A. Pervin, \& O. P. John (Eds.), Handbook of personality: Theory and research (Vol. 2, pp. 102-138). New York: Guilford Press.

Jöreskog, K. G. (1973). A General Method for Estimating a Linear Structural Equation System. In A. Goldberger, \& O. D. Duncan (Eds.), Structural Equation Models in the Social Sciences (pp. 85-112). New York: Academic Press.

Jöreskog, K. G. (1969). A general approach to confirmatory maximum likelihood factor analysis. Psychometrika, 34, 183-202. http://dx.doi.org/10.1007/BF02289343

Jöreskog, K. G., \& Sörbom, D. (2001). LISREL 8 User's Reference Guide. Chicago: Scientific Software International.

Kaiser, H. F. (1958). The Varimax Criterion for Analytic Rotation in Factor Analysis. Psychometrika, 23, 187-200. http://dx.doi.org/10.1007/BF02289233

Koopmans, T. (1945). Statistical Estimation of Simultaneous Economic Relations. Journal of the American Statistical Association, 40, 488-466. http://dx.doi.org/10.1080/01621459.1945.10500746

Lawley, D. N. (1940). The Estimation of Factor Loadings by the method of Maximum Likelihood. Proceedings of the Royal Society of Edinburgh, 60, 64-82.

Long, J. S. (1983). Confirmatory Factor Analysis: A Preface to LISREL. Bloomington, IN: Sage Publications.

MacKenzie, S., Podsakoff, P., \& Jarvis, C. (2005). The Problem of Measurement Model Misspecification in Behavioural and Organizational Research and some Recommended Solutions. Journal of Applied Psychology, 90(4), 710-730. http://dx.doi.org/10.1037/0021-9010.90.4.710

McDonald, R. P. (1970). The theoretical foundations of principal factor analysis, canonical factor analysis, and 
alpha factor analysis. British Journal of Mathematical and Statistical Psychology, 23, 1-21. http://dx.doi.org/10.1111/j.2044-8317.1970.tb00432.x

Matsueda R. L. (2012). Key Advances in The History Of Structural Equation Modeling.Handbook of Structural Equation Modeling. New York, NY: Guilford Press

Mosier, C. I. (1939). Determining a simple structure when loadings for certain tests are known. Psychometrika, 4 , 149-162. http://dx.doi.org/10.1007/BF02288493

Mislevy, R. J. (1984). Estimating latent distributions. Psychometrika, 49, 359-381. http://dx.doi.org/10.1007/BF02306026

Morales, M. G. (2011). Partial Least Squares (PLS) Methods: Origins, Evolution, and Application to Social Sciences. Communications in Statistics Theory and Methods, 40(13), 2305-2317. http://dx.doi.org/10.1080/03610921003778225

Muthén, B. (1984). A General Structural Equation Model with Dichotomous, Ordered Categorical, and Continuous Latent Variable Indicators. Psychometrika, 49, 115-132. http://dx.doi.org/10.1007/BF02294210

Muthén, B. (1994). Multi-Level Covariance Structure Analysis. Sociological Methods and Research, 22, 376-398. http://dx.doi.org/10.1177/0049124194022003006

Muthén, B., \& Muthén. L. K. (2004). Mplus User's Guide. Los Angeles, CA.

Norman, W. T. (1963). Toward an adequate taxonomy of personality attributes: Replicated factor structure in peer nomination personality ratings. Journal of Abnormal and Social Psychology, 66, 574-583. http://dx.doi.org/10.1037/h0040291

Nunnally, J. C. (1978). Psychometric Theory (2nd ed.). New York: McGraw-Hill.

Petter, S., Straub, D., \& Rai, A. (2007). Specifying Formative Constructs in Information Systems Research. MIS Quarterly, 31(4), 623-656.

Pearl, J. (2000). Causality: Models, Reasoning, and Inference. Cambridge, UK: Cambridge University Press.

Pearson, K. (1901). On Lines and Planes of Closest Fit to Systems of Points in Space. Philosophical Magazine, 6, 559-572. http://dx.doi.org/10.1080/14786440109462720

Rabe-Hesketh, S, Skrondal, A., \& Pickles, A. (2004). Generalized Multilevel Structural Equation Modeling. Psychometrika, 69, 167-190. http://dx.doi.org/10.1007/BF02295939

Rigdon, E. E. (2012). Rethinking Partial Least Squares Path Modeling: In Praise of Simple Methods. Long Range Planning, 45, 341-355. http://dx.doi.org/10.1016/j.lrp.2012.09.010

Roesch, S. C., Aldridge, A. A., Stocking, S. N., Villodas, F., Leung, Q., Bartley, C. E., \& Black, L. J. (2010). Multilevel factor analysis and structural equation modeling of daily dairy coping data: Modeling trait and state variation. Multivariate Bahavioural Research, 467-789. http://dx.doi.org/10.1080/00273171.2010.519276

Roldán, J. L., \& Sánchez-Franco, M. J. (2012). Variance-Based Structural Equation Modeling: Guidelines for Using Partial Least Squares in Information Systems Research. In Research Methodologies, Innovations and Philosophies in Software Systems Engineering and Information Systems (pp. 193-221). http://dx.doi.org/10.4018/978-1-4666-0179-6.ch010

Shipley, B. (2000). Cause and Correlation in Biology: A User's Guide to Path Analysis, Structural Equations and Causal Inference. Cambridge, UK: Cambridge University Press. http://dx.doi.org/10.1017/CBO9780511605949

Skrondal, A., \& Rabe-Hesketh, S. (2004). Generalized Latent Variable Modeling: Multilevel, Longitudinal, and Structural Equation Models. Boca Raton: Chapman and Hall. http://dx.doi.org/10.1201/9780203489437

Spearman, C. (1904). General Intelligence, Objectively Determined and Measured. American Journal of Psychology, 15, 201-293. http://dx.doi.org/10.2307/1412107

Steiger, J. H., \& Schönemann, P. H. (1978). A history of factor indeterminacy. In S. Shye (Ed.), Theory construction and data analysis. Chicago: University of Chicago Press.

Thomson, G. H. (1916). A hierarchy without a general factor. British Journal of Psychology, 8, 271-281.

Thomson, G. H. (1935). The definition and measurement of "g" (general intelligence). Journal of Educational Psychology, 26, 241-262. http://dx.doi.org/10.1037/h0059873 
Thurstone, L. L. (1935). The Vectors of Mind. Chicago: University of Chicago Press.

Thurstone, L. L. (1947). Multiple factor analysis. Chicago: Chicago University Press.

Tucker, R. (1955). The Objective Definition of Simple Structure in Linear Factor Analysis. Psychometrika, 20, 209-225. http://dx.doi.org/10.1007/BF02289018

Van der Linden, D., Nijenhaus, J., \& Bakker, A. B. (2010). A general factor of personality: A meta-analysis of big five intercorrelations and a criterion-related validity study. Journal of Research in Personality, 44, 315-327. http://dx.doi.org/10.1016/j.jrp.2010.03.003

Wilson, E. B. (1928a). Review of 'The abilities of man, their nature and measurement' by C. Spearman. Science, 67, 244-248. http://dx.doi.org/10.1126/science.67.1731.244

Wilson, E. B. (1928b). On hierarchical correlation systems. Proceedings of the National Academy of Sciences, 14, 283-291. http://dx.doi.org/10.1073/pnas.14.3.283

Wilson, E. B. (1929a). Review of 'Crossroads in the mind of man: A study of differentiable mental abilities' by T. L. Kelley. Journal of General Psychology, 2, 153-169.

Wilson, E. B. (1929b). Comments on Professor Spearman's note. Journal of Educational Psychology, 20, 217-223. http://dx.doi.org/10.1037/h0071925

Wold, H. (1979). Model construction and evaluation when theoretical knowledge is scarce: Theory and application of partial least squares. In J. Kmenta, \& J. B. Ramsey (Eds.), Evaluation of econometric models (pp. 47-74). New York: Academic.

\section{Copyrights}

Copyright for this article is retained by the author(s), with first publication rights granted to the journal.

This is an open-access article distributed under the terms and conditions of the Creative Commons Attribution license (http://creativecommons.org/licenses/by/3.0/). 